\title{
Sequential Laser and EDM Micro-drilling for Next Generation Fuel Injection Nozzle Manufacture
}

\author{
Lin Li (2) ${ }^{1}$, C. Diver ${ }^{2}$, J. Atkinson ${ }^{1}$, R. Giedl-Wagner ${ }^{3}$, H. J. Helml ${ }^{3}$ \\ ${ }^{1}$ School of Mechanical, Aerospace and Civil Engineering, The University of Manchester, UK \\ ${ }^{2}$ DELPHI Technical Centre Gillingham, Kent, UK \\ ${ }^{3} \mathrm{GFH}-\mathrm{mbH}$, Deggendorf, Germany
}

\begin{abstract}
High quality holes of diameters less than $145 \mu \mathrm{m}$ are required for the manufacture of next generation diesel fuel injection nozzles for improved combustion efficiency and reduction of emission to the environment. The current practice of using electro-discharge machining (EDM) drilling of fuel injection nozzles is limited in terms of the hole size it can produce effectively and the length of time needed to drill. In addition, the tooling cost is high. This paper reports on an investigation into a sequential laser and EDM micro-drilling technique for the manufacture of next generation fuel injection nozzles. A laser-drilled pilot hole is rimmed out by EDM drilling. It was found that this hybrid process has eliminated the problems of recast and heat affected zones typically associated with the laser drilling process. The new process has enabled a $70 \%$ reduction in total drilling time compared to standard EDM drilling as less material is removed by the EDM. The quality of the holes is as good as direct EDM drilling, thus eliminating the need for re-certification of the drilling process. Various combinations of laser/EDM drilling conditions have been examined. Optimum diameters for the pilot hole and the EDM electrode have been identified for a particular diameter of fuel injection nozzle, giving the minimum total drilling time and the best quality holes. A special system was designed to enable the alignment of nozzles to be controlled to within $\pm 20 \mu \mathrm{m}$. The technique has enabled valuable cost savings and increase in production capacity for next generation fuel injection nozzle manufacture.
\end{abstract}

Keywords:

Laser micro machining, electrical discharge machining (EDM), drilling

\section{INTRODUCTION}

The demand for higher energy efficiency and less pollutant emissions to the environment requires hole sizes in diesel fuel injection nozzles to less than $145 \mu \mathrm{m}$ in diameter over a $1 \mathrm{~mm}$ wall thickness of hardened steels. Current production techniques based on EDM drilling are therefore faced with new challenges. As the holes are getting smaller, tooling cost is higher as frequent breakage of electrodes occurs [1]. In addition, material removal rate will be lower [1-2]. Typically, drilling time is 30 seconds per hole using EDM technology. Attempts have been made by a number of research groups and companies to use nanosecond pulsed laser drilling instead of EDM. However, the hole quality cannot meet the industrial standard as laser drilling typically produces larger recast and heat affected zones [3]. Although the use of peco-second and femtosecond lasers could provide better quality holes [4], the drilling time is too long based on currently available commercial laser systems. Li and Achara [5] demonstrated a chemically-assisted laser machining technique to minimise recast and heat affected zones while increasing the material removal rate during laser drilling and micromachining. The technique is not yet mature enough for large scale industrial applications. Hybrid laser and mechanical machining was studied by Brown [6] for drilling high quality shaped cooling holes in turbine airfoils to replace the traditional EDM drilling technology. These holes are typically $0.4-0.6 \mathrm{~mm}$ in diameter. Combined microlithography and electroplating has been investigated for the fabrication of spiral metal fuel injector nozzle arrays
[7]. Micro-EDM drilling of reverse tapered holes $(100 \mu \mathrm{m}$ diameter at electrode entry and $160 \mu \mathrm{m}$ diameter at electrode exit) for fuel injection nozzle manufacture was demonstrated by Diver et al using multiple axis rotary systems [8].

The aim of the present investigation is to understand the feasibility and characteristics of using a combined laser and EDM drilling technique to produce $140 \mu \mathrm{m}$ diameter holes in diesel fuel injection nozzles. In this technique, pilot holes are first drilled by a nano-second pulsed laser beam. The holes are then finished by EDM drilling. The quality of the holes is assessed along with the drilling efficiency in comparision with traditional EDM drilling. Alignment of the EDM eletrodes with the pilot holes and cost implications of the technique are analysed.

\section{EXPERIMENTAL PROCEDURE}

Two different lasers were used in the experiment to study the effect of laser pulse length. A GSI-Lumonic Spectron SL650T Nd:YAG laser (1064 nm wavelength) with 10-40 $\mu$ s pulse length at a repetition rate of up $2000 \mathrm{~Hz}$ with 15 $\mathrm{mJ} / \mathrm{pulse}$ and a Spectra Physics Powergator diode pumped solid state (DPSS) laser (1064 $\mathrm{nm}$ wavelength) with $15 \mathrm{~ns}$ pulse length at a repetition rate up to $10 \mathrm{kHz}$ with up to $2.7 \mathrm{~mJ} / \mathrm{pulse}$ were used for the drilling of pilot holes. A Posalux Microfor HP2 EDM machine was used to finish the hole to the desired dimension. The EDM drilling parameters used were within $60-250 \mathrm{~V}$, pulse length 50 - 
$2000 \mathrm{~ns}$, pulse frequency of $10-2000 \mathrm{kHz}$ and $0.005-3 \mathrm{~A}$ current.

Initially, holes were drilled in $1 \mathrm{~mm}$ flat plates of a $2 \%$ nickel - $2 \%$ chromium case hardened steel to simulate hole drilling of a fuel injection nozzle, with the added ease of evaluating a flat plate compared to a nozzle. Real fuel injection nozzles (with the same material and wall thickness as the test plates) were drilled using optimum process parameters gained from the flat plate drilling. Initial trials focused on the optimum laser hole to minimise the EDM hole drilling time. Laser holes from $10 \mu \mathrm{m}$ to $120 \mu \mathrm{m}$ in steps of $10 \mu \mathrm{m}$ were drilled. The target final hole diameter after EDM drilling was $140 \mu \mathrm{m}$. Positive and negative tapered, parallel and blind holes were produced to determine which would give the most efficient EDM cycle time. The laser holes were then measured using Zeiss optical microscopy and image analysis methods for entry and exit diameters and plastic impressions of the holes were also taken to assess the actual 3-D hole shape after processing.

Accurate fixturing (within $1 \mu \mathrm{m}$ ) was developed to aid alignment of the laser drilled hole to the EDM electrode for flat plate drilling ( $\pm 20 \mu \mathrm{m}$ for nozzle drilling). The EDM process used deionised water which is the standard used for drilling diesel fuel injection nozzles. Solid tungsten carbide electrodes were used in the EDM drilling experiments. EDM parameter optimisation was carried out to achieve the optimum processing time. The EDM electrode was dressed using a new on-line cutting method between each hole drilling (takes 1 second), thus allowing time saving compared to standard EDM electrode dressing by reversing the electrode polarity (takes 4 seconds). The electrode shape was analysed after drilling each hole to evaluate the effect of drilling pre-drilled holes on electrode wear. Image analysis was developed to detect if holes were misaligned. Scanning electron microscopy (SEM) was used to evaluate the morphology and microstructure of holes drilled. Figure 1 illustrates the combined laser and EDM drilling. The laser drilled hole diameter, size of heat affected zone and the final hole diameter requirement determine the size of EDM electrode diameter.

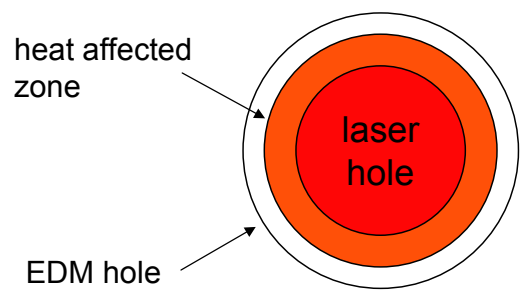

Figure 1: Illustration of combined laser and EDM drilling.

\section{RESULTS}

\subsection{Proof of concept}

Initial trials to prove the concept showed that the cycle time of EDM could be reduced from 40 seconds to 20 seconds by using a laser-drilled pilot hole. The initial laser hole was approximately $60 \mu \mathrm{m}$ in diameter and the final EDM hole was $140 \mu \mathrm{m}$ in diameter.

\subsection{Optimum laser pre-hole diameter and shape}

Laser holes with parallel, positive and negative tapered and blind form of various entry and exit diameter combinations were produced as shown in Figure 2. The target was to produce a final hole diameter of $140 \mu \mathrm{m}$, using a $110 \mu \mathrm{m}$ diameter electrode in the shortest drilling time. An $80 \mu \mathrm{m}$ parallel laser hole was found to be the optimum diameter and shape of laser pre-hole to result in the fastest EDM cycle time. An EDM cycle time of 10 seconds ( 1 second laser drilling plus 9 seconds EDM) was achieved compared to 32 seconds without the pilot hole. If electrode dressing time is also considered (4 sec for standard EDM and $1 \mathrm{sec}$ for laser-EDM), it would give a $70 \%$ reduction in the time to produce a $140 \mu \mathrm{m}$ diameter hole with EDM.

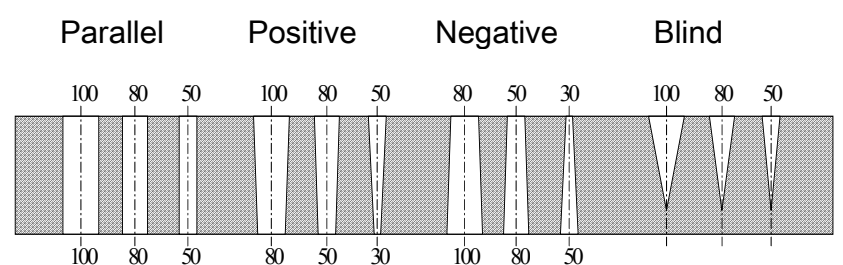

Figure 2: Various laser hole forms.

\subsection{Hole quality evaluation}

Figure 3 shows a plastic impression which was taken of an $80 \mu \mathrm{m}$ diameter laser hole. The hole was produced by laser processing in a time of approximately $1 \mathrm{sec}$. Figure 4 shows a plastic impression which was taken of the final EDM hole of $140 \mu \mathrm{m}$ diameter. Significant improvement in hole quality after the EDM is seen.

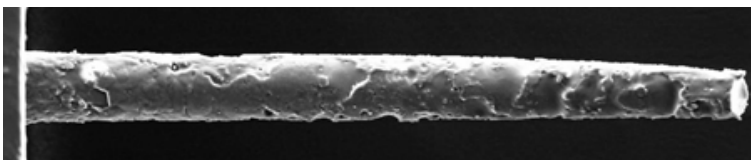

Figure 3: SEM image of a plastic impression of a laser drilled pre-hole. $\varnothing 80 \mu \mathrm{m}$ drilled in 1-2 seconds.

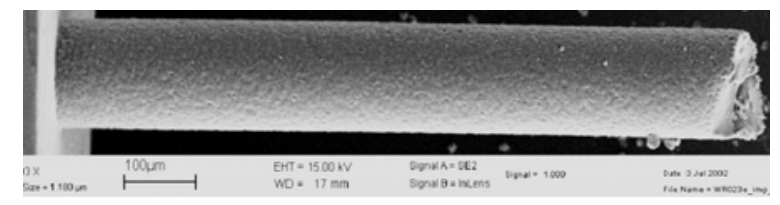

Figure 4: SEM image of a plastic impression of a laserEDM hole following EDM drilling. $\varnothing 140 \mu \mathrm{m}$ drilled by EDM in 9 seconds.

Figure 5 shows an SEM image of a sectioned hole which was produced by EDM hole drilling. Figure 6 shows an SEM image of a sectioned hole produced with sequential laser and EDM drilling. As one might expect, these verify that the laser-EDM holes are of a similar quality to holes produced by standard EDM. It should be noted that a honing process is employed to clean the hole walls for both the standard EDM and laser-EDM processes.

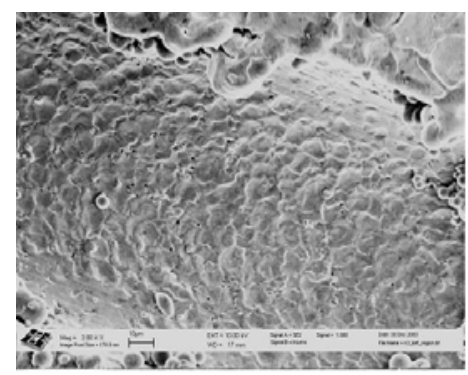

Figure 5: SEM image of a sectioned hole produced by standard EDM (x 2000). 


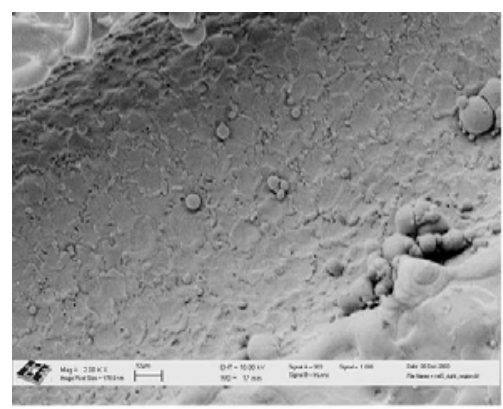

Figure 6: SEM image of a hole produced by laser followed by EDM micro-drilling (i.e. Laser-EDM). ( x 2000).

Figure 7 compares the laser pilot, standard EDM drilled and laser-EDM drilled holes. The hole diameter produced by laser-EDM $(140 \mu \mathrm{m})$ is smaller than the hole resulting from standard EDM $(146 \mu \mathrm{m})$ using the same sized EDM electrode. Thus a smaller radial overcut occurs with laserEDM.

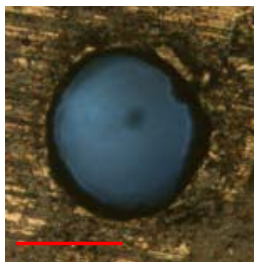

(a)

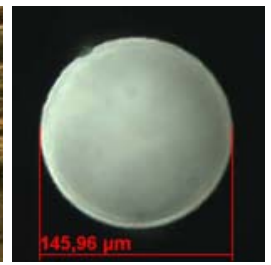

(b)

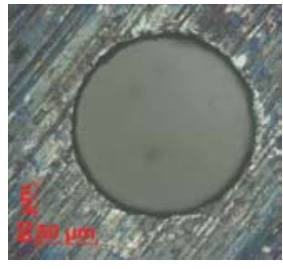

(c)
Figure 7: Comparison of laser pilot hole (a), standard EDM drilled hole (b), and laser-EDM hole (c).

\subsection{HAZ and recast evaluation}

Optimised results showed that a heat affected zone (HAZ) of approximately $15 \mu \mathrm{m}$ radially surrounded the laser hole using Spectron Nd:YAG laser percussion drilling. Therefore, to fully remove the HAZ, a minimum final EDM hole diameter of $110 \mu \mathrm{m}$ was required. This also highlighted the need for accurate position of the centre of the laser hole with the final EDM hole. The type of laser used can affect the size of the HAZ zone. The longer pulsed Spectron Nd:YAG laser produced holes much more quickly (typically 1 second drilling time) than the shorter pulsed Powergator DPSS laser (10-15 seconds). However, the shorter pulsed DPSS laser produced smaller HAZ and thinner recast; typically 2-3 $\mu \mathrm{m}$. Figure 8 shows a sectioned laser hole (not optimised) drilled using Spectron and the light region is the recast layer around the hole.

The hardness in the region close to the hole wall was measured to determine if the value of hardness was affected by the laser process. The hardness specification for a fuel injection nozzle was at $625 \mathrm{HV}$. There is no remaining evidence of a laser recast region following the EDM process.

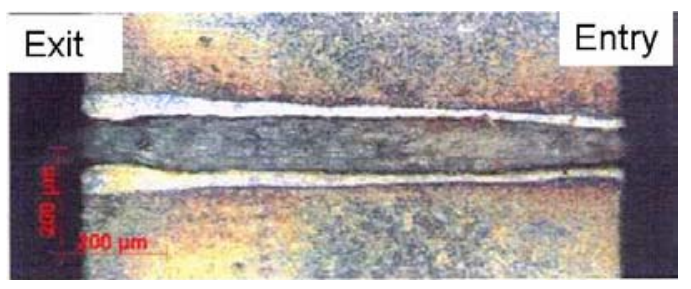

Figure 8: A sectioned laser hole with a recast region.

\subsection{Hole diameters and nozzle drilling}

Figure 9a shows the entry and exit diameters for the $80 \mu \mathrm{m}$ parallel laser hole, using the Spectron Nd:YAG laser percussion drilling employing combined focal position and pulsed energy control [9]. 68 holes were produced and measured. The average laser hole entry diameter was 80.9 $\mu \mathrm{m}$ and the average laser hole exit diameter was $80.7 \mu \mathrm{m}$. The standard deviation for hole entry was $1.5 \mu \mathrm{m}$ and the standard deviation for hole exit was $3.3 \mu \mathrm{m}$.

After the EDM drilling of the laser pilot holes (Figure 9b), it was noted that the holes were more parallel than what was seen with standard EDM. This is believed to be due to secondary erosion as debris exits the hole being produced. The average hole entry diameter was $137 \mu \mathrm{m}$ and the hole exit diameter was $136.9 \mu \mathrm{m}$. This shows that the holes are parallel. The standard deviation for hole entry was $1.9 \mu \mathrm{m}$ and the hole exit was $1.2 \mu \mathrm{m}$.

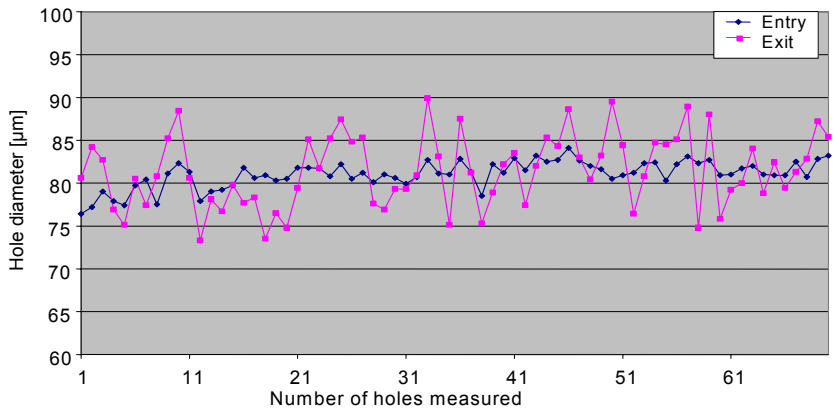

(a)

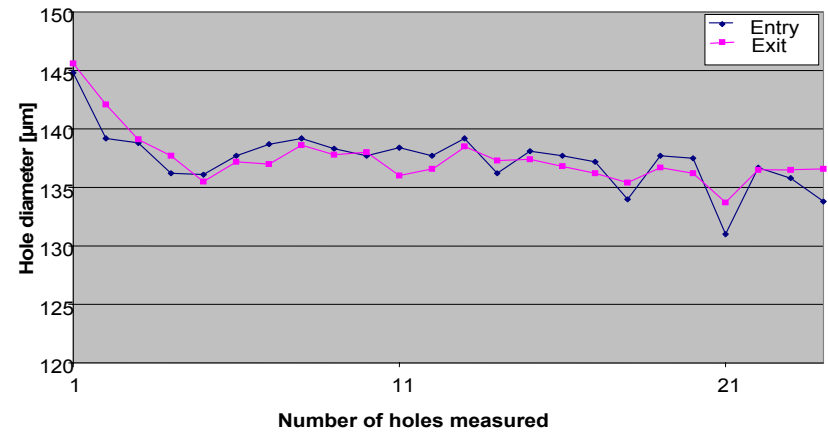

(b)

Figure 9: Distribution of entry and exit diameters for (a) laser pilot holes and (b) Laser-EDM holes.

Based on the optimised operating parameters gained from the flat plate drilling, 30 real fuel injection nozzles were drilled using the laser-EDM technique. Figure 10 shows an example where back wall damage prevention was not implemented. The quality of the holes was acceptable from a manufacturing point of view by Delphi as a fuel injection equipment supplier.

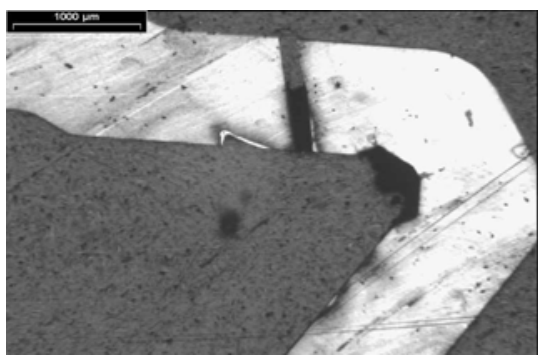

Figure 10: An example of laser-EDM drilled diesel fuel injection nozzle. 


\subsection{Laser-EDM drilling alignment}

Alignment was a critical issue for this process, as misalignment of the laser could have a significant effect on spray in a fuel injection nozzle in that it could affect the spray targeting in the combustion chamber and the type of spray produced. Figure 11 shows a view of a nozzle including the dowel hole position, the fuel feed hole, the guide hole and also a side view of the nozzle showing the internal reference position of the nozzle.

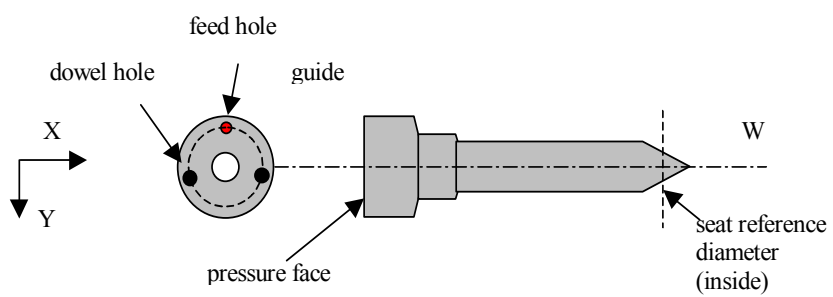

Figure 11: Schematic view of the nozzle showing the guide, dowel and fuel feed holes.

A set of pins was designed that could be used on both the laser fixture and the EDM fixture to minimise variation and to keep hole position within $\pm 20 \mu \mathrm{m}$. The pins were designed to be self-centring (Figure 12) and used in the dowel hole. There was a separate pin used in a guide hole but this was to ensure that the nozzle could not be mounted in the wrong way.

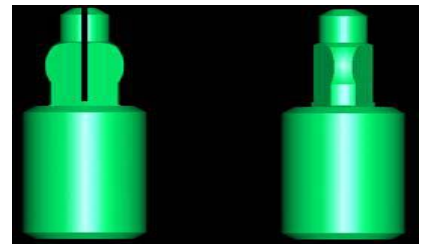

Figure 12: Illustration of self-centring alignment pins.

\section{DISCUSSION}

There are many benefits associated with adopting this method of producing micro-holes in fuel injection nozzles. The present work has shown a $42 \%$ reduction in the cost of producing the holes (excluding the initial capital investment). This is mainly due to the drastic reduction in total cycle time. Thus labour cost per nozzle is reduced. There should be no customer requirement for validating engine performance as a result of the new approach. The authors estimated that the production capacity of a typical EDM nozzle hole production cell can be increased by $90 \%$ for $140 \mu \mathrm{m}$ holes (or higher for smaller holes as it will take longer time for the standard EDM) by introducing this process. Therefore no additional investment will be needed for future increases in capacity after the initial laser system installation. One laser system can feed the nozzles to 6-8 EDM machines.

The work presented in this paper has shown that the hole drilling cycle time can be reduced by up to $70 \%$. Electrode wear has changed from the standard EDM type to a tapered end since the wear is mainly radial in laser-EDM. Final hole diameter, $H$ is related to electrode diameter, $D$ and radial gap, $g$ by the expression [2]:

$$
H=2 g+D
$$

In the present work, a $110 \mu \mathrm{m}$ diameter electrode was used. The standard EDM process produced a 142-146 $\mu \mathrm{m}$ hole diameter giving an average radial gap of 16-18 $\mu \mathrm{m}$. In the case of a hole which had been pilot drilled by means of a laser followed by EDM drilling with a $110 \mu \mathrm{m}$ diameter electrode, the final measured hole was 137-140 $\mu \mathrm{m}$ diameter giving a radial gap of $13.5-15 \mu \mathrm{m}$. The reduced radial gap arises because a higher drilling speed is obtained when a pilot hole is present, since less material has to be removed. This allows less time for radial machining to occur. Moreover, in standard EDM, the debris particles in the used dielectric may act as nuclei to promote machining in the narrow radial gap. In the laserEDM process, the debris and used dielectric fluid flow through the pilot hole thus eliminating this effect.

\section{CONCLUSION}

A novel combined laser and EDM drilling technique has been demonstrated to achieve reduced drilling time by $70 \%$, cost reduction by $42 \%$ and production capacity increase by $90 \%$ without compromising the hole quality as compared to standard EDM drilling. In addition, the hole size can be reduced to meet the requirement for the next generation fuel injection nozzle manufacture. The work has shown that, to achieve a final hole diameter of 137-140 $\mu \mathrm{m}$, the optimum drilling configuration is a $80 \mu \mathrm{m}$ diameter parallel laser pilot hole, followed by EDM drilling using a $110 \mu \mathrm{m}$ diameter electrode. As the debris and dielectric fluid flow are through the pilot holes during the laser-EDM drilling, a much reduced radial gap has been observed compared to standard EDM drilling. In addition, as the materials to be removed are much less in the EDM drilling stage, the drilling time is much reduced and drilling efficiency increased compared to standard EDM drilling.

\section{REFERENCES}

[1] Pham, D.-T., Dimov, S.-S., Bigot, S., Ivanov, A., Popov, K., 2004, Micro-EDM - Recent Developments and Research Issues, Journal of Materials Processing Technology, 149: 50-57.

[2] Weng, F., Her, M., 2002, Study of the Batch Production of Micro Parts Using EDM Process, International Journal of Advanced Manufacturing Technology, 19:266-270.

[3] Dausinger, F., 2000, Precise Drilling with Short Pulsed Lasers, in High-Power Lasers in Manufacturing, Proceedings of SPIE, 3888: 180-187.

[4] Meijer, J., Du, K., Gillner, A., Hoffmann, D., Kovalenko, V., Masuzawa, T., Ostendorf, A., Poprawe, R.., Schulz, W., 2002, Laser Machining by Short and Ultrashort Pulses, State of the Art, Annals of the CIRP, Manufacturing Technology, 51/2: 1-20.

[5] Li, L., Achara, C., Chemical Assisted Laser Machining for Minimisation of Recast and Heat Affected Zone, 2004, Annals of the CIRP, Manufacturing Technology, 53/1: 175-178.

[6] Brown, R.-T., 2000, Hybrid Laser Process for Shaped Turbine-Airfoil Cooling Holes, Proc. of ICALEO'99, Publ. Laser Institute of America, FL, USA, 87/1: 205212.

[7] Morris, T.-E., Murphy, M.-C., Acharya, S., 2000, Micro Fabrication of a metal Fuel Injector Nozzle Array, Proceedings of SPIE, 4171: 58-65.

[8] Diver, C., Atkinson, J., Helml, H.-J., Li, L., 2004, Micro-EDM Drilling of Tapered Holes for Industrial Applications, Journal of Materials Processing Technology, 149/1-3: 296-303.

[9] Li, L., Low, D.-Y., Ghoreshi, M., 2002, Hole Taper Characterisation and Control in Laser Percussion Drilling, Annals of the CIRP, Manufacturing Technology, 51/1: 153-156. 